\title{
Pengaruh Komposisi Biodisel Jagung Terhadap Sifat-Sifat Campuran Biodisel Jatropha-Jagung
}

(Effect of Composition of Corn Biodiesel on the Properties of Jatropha-Corn Biodiesel Blends)

\author{
WAHYUDI, ANDRE SASUTA, MUHAMMAD NADJIB
}

\begin{abstract}
ABSTRAK
Biodisel merupakan bahan bakar alternatif untuk mesin disel yang biasanya terbuat dari minyak nabati. Minyak jatropha dan minyak jagung merupakan bahan baku biodisel yang potensial. Namun biodisel dari bahan baku minyak jatropha memiliki kelemahan, diantaranya adalah viskositas yang relatif tinggi dan nilai kalor yang relatif rendah. Salah satu upaya perbaikannya adalah pencampuran dengan minyak jagung. Penelitian ini bertujuan untuk mengetahui pengaruh dari variasi komposisi campuran terhadap karakteristik biodisel. Kedua jenis bahan baku diproses menjadi biodisel melalui reaksi transesterifikasi. Selanjutnya dilakukan pencampuran antara biodisel jatropha dan biodiesel jagung. Campuran dibuat dalam sembilan variasi komposisi. Setiap komposisi campuran diaduk dan dipanaskan pada suhu $90{ }^{\circ} \mathrm{C}$ selama 60 menit. Hasil penelitian menunjukkan bahwa campuran biodisel jatropha dan jagung memiliki viskositas yang lebih rendah daripada biodisel jatropha murni. Densitas dan titik nyala campuran biodisel tersebut juga mengalami penurunan. Hasil lainnya adalah nilai kalor biodiesel campuran lebih tinggi daripada nilai kalor biodiesel jatropha murni.
\end{abstract}

Kata kunci: asam lemak, densitas, viskositas, biodiesel, jatropha, jagung

\section{ABSTRACT}

Biodiesel is an alternative fuel for diesel engines that are usually made from vegetable oil. Jatropha and corn oil are potential biodiesel feedstocks. However, biodiesel from jatropha oil has disadvantages, including high viscosity and relatively low heating value. An effort to improve its properties is mixing it with corn oil. The purpose of this study was to determine the effect of the composition of the mixture on the biodiesel properties. Both raw materials were processed into biodiesel through transesterification reactions. The next step is mixing jatropha and corn biodiesel. There were nine variations of the biodiesel mixture. Each mixture was stirred and heated at $90{ }^{\circ} \mathrm{C}$ for 60 minutes. The results showed that the mixture of jatropha and corn biodiesel had lower viscosity than pure jatropha biodiesel. Density and flash point of the biodiesel mixture also decreased. The heating value of mixed biodiesel is higher than its of pure jatropha biodiesel.

Keywords: fatty acid, density, viscosity, biodiesel, jatropha, corn

\section{PENDAHULUAN}

Semakin meningkatnya jumlah penduduk di berbagai kawasan di dunia mengakibatkan meningkatnya kebutuhan energi (Gopal, 2014). Salah satunya adalah berupa kebutuhan bahan bakar. Keterbatasan cadangan bahan bakar fosil mengharuskan adanya bahan bakar alternatif.

Biodisel yang terdiri dari campuran mono-alkil ester dari asam lemak rantai panjang, adalah bahan bakar alternatif untuk mesin diesel yang dibuat dari minyak nabati atau lemak hewan (Eloka-Eboka et al., 2017). Beberapa keuntungan dari penggunaan biodisel diantaranya biodisel berasal dari sumber yang dapat diperbaharui dan mudah ditemukan, dapat terurai secara biologis dan dapat mengurangi emisi gas buang (Eloka-Eboka et al., 2017). Biodisel juga memiliki bilangan setana $(\mathrm{Cn})$ dan titik nyala yang lebih tinggi dari minyak diesel (Crabbe et al., 2001). 
Salah satu minyak nabati yang potensial untuk digunakan sebagai bahan baku biodisel adalah minyak jatropha (Pramanik, 2003; Sarin et al., 2007). Minyak jatropha merupakan minyak nabati yang termasuk dalam kategori nonpangan, sehingga penggunaanya sebagai bahan baku biodisel tidak berpengaruh terhadap ketersediaan bahan pangan (Nisar, 2017).

Meskipun memiliki beberapa kelebihan, namun biodisel jatropha mempunyai nilai viskositas yang tinggi dan nilai kalor yang relatif rendah (Abed, 2018). Viskositas yang tinggi akan menyebabkan bahan bakar sulit dikabutkan di ruang bakar. Nilai kalor biodisel secara umum $10 \%$ lebih rendah dari bahan bakar diesel fosil (Hoekman et al., 2012). Upaya untuk mengatasi kelemahan biodisel tersebut harus dilakukan agar biodisel sebagai bahan bakar alternatif semakin menarik untuk digunakan.

Minyak nabati lain yang dapat digunakan sebagai sebagai bahan baku biodisel adalah minyak jagung (El Boulifi et al., 2010; Shehata et al., 2015). Minyak jagung memiliki kandungan trigliserida sekitar 98,6 \% sisanya adalah bahan non minyak sesperti zat warna, lilin dan abu (Sidabutar et al., 2013).

Sifat fisik dan kimia biodisel sangat dipengaruhi oleh asam lemak pembentuknya (Silitonga et al., 2013). Viskositas, densitas, angka setana dan nilai yodium dipengaruhi oleh ketidakjenuhan asam lemak. Meningkatnya ketidakjenuhan asam lemak akan menyebabkan penurunan angka setana dan stabilisasi oksidasi yang rendah. Panjang rantai asam lemak juga dapat berpengaruh pada sifat fisik biodisel namun tingkat korelasinya tidak terlalu tinggi (Hoekman et al., 2012). Setiap bahan baku minyak nabati memiliki komposisi asam lemak yang berbedabeda. Untuk mendapatkan sifat biodisel yang optimal diperlukan perubahan komposisi asam lemak dari minyak nabati. Salah satu alternatif untuk mengubah komposisi asam lemak adalah dengan pencampuran antara minyak nabati yang memiliki komposisi berbeda (Wahyudi et al., 2019).

Minyak jagung diperkirakan memiliki komposisi asam lemak yang berbeda dengan minyak jatropha. Pencampuran antara minyak jatropha dengan minyak jagung diharapkan dapat memperbaiki sifat fisik biodisel jatropha. Tujuan penelitian ini adalah untuk mengetahui pengaruh variasi komposisi campuran minyak jatropha dan minyak jagung sebagai bahan baku biodisel terhadap sifat fisik biodisel.

\section{Metode Penelitian}

Bahan utama penelitian ini adalah minyak jatropha dan minyak jagung sebagai bahan baku biodisel. Bahan lainnya adalah methanol 99\% dan kalium hidroksida (KOH). Sifat fisik minyak jatropha dan minyak jagung disajikan pada Tabel 1.

TABEL 1. Sifat fisik minyak jatropha dan minyak

\begin{tabular}{lrr}
\hline \multicolumn{3}{c}{ jagung } \\
Sifat & $\begin{array}{r}\text { Minyak } \\
\text { Jatropha }\end{array}$ & $\begin{array}{r}\text { Minyak } \\
\text { Jagung }\end{array}$ \\
\hline Densitas, $40{ }^{\circ} \mathrm{C}\left(\mathrm{kg} / \mathrm{m}^{3}\right)$ & 937.74 & 881.93 \\
Viskositas kinematik, & & \\
$40{ }^{\circ} \mathrm{C}(\mathrm{cSt})$ & 193.55 & 27.21 \\
Titik Nyala $\left({ }^{\circ} \mathrm{C}\right)$ & 309.67 & 326 \\
Nilai Kalor $(\mathrm{MJ} / \mathrm{kg})$ & 37.16 & 39.64 \\
\hline
\end{tabular}

Minyak jatropha dan minyak jagung disiapkan untuk diproses menjadi biodisel melalui proses transesterifikasi. Bahan baku minyak nabati dan methanol direaksikan dengan bantuan $\mathrm{KOH}$ sebagai katalis. Reaksi dilakukan selama 60 menit pada temperatur $65{ }^{\circ} \mathrm{C}$. Hasil reaksi transesterifikasi ini adalah biodisel dan gliserol. Setelah proses pengendapan selama 8 jam, gliserol dipisahkan dari biodisel. Proses selanjutnya adalah pencucian biodisel untuk menghilangkan kotoran dan pengeringan untuk mengurangi kadar air.

Selanjutnya dilakukan pencampuran biodisel jatropha dan biodisel jagung pada beberapa variasi komposisi. Variasi pertama adalah 900 $\mathrm{ml}$ biodisel jatropha dan $100 \mathrm{ml}$ biodisel jagung. Variasi berikutnya adalah $800 \mathrm{ml}$ biodisel jatropha dan $200 \mathrm{ml}$ biodisel jagung, demikian seterusnya sampai dengan $100 \mathrm{ml}$ biodisel jatropha dan $900 \mathrm{ml}$ biodisel jagung. Setiap variasi campuran diaduk dan dipanaskan pada temperatur $90{ }^{\circ} \mathrm{C}$ selama 60 menit. Temperatur dijaga tetap selama proses pencampuran.

Setiap variasi biodiesl diuji sifat-sifatnya meliputi densitas, viskositas, titik nyala dan nilai kalor. Pengukuran densitas dilakukan dengan menimbang $50 \mathrm{ml}$ sampel pada temperatur $40{ }^{\circ} \mathrm{C}$ menggunakan timbangan digital Fujitsu FS-AR210. Densitas ( $\rho$ ) diperoleh dari perhitungan massa terhadap volume sampel. Pengukuran viskositas dilakukan pada temperatur sampel $40{ }^{\circ} \mathrm{C}$, 
menggunakan Viscometer NDj 8 S. Pengujian nilai kalor biodisel dilakukan menggunakan Bomb Calorimeter Parr 6050. Titik nyala diukur menggunakan metode Cleveland Open Cup. Komposisi asam lemak biodisel jatropha dan biodisel jagung dilakukan menggunakan Shimadzu Gas Chromatography (GC) 2010.

\section{HASIL DAN PEMBAHASAN}

\section{Komposisi Asam Lemak}

Komposisi asam lemak biodisel jatropha dan biodisel jagung diuji menggunakan Gas Chromatography. Komposisi asam lemak biodisel jatropha dan biodisel jagung ditunjukkan pada Tabel 2. Biodisel jatropha terutama terdiri dari Linolelaidic Acid Methyl Ester dan Methyl Palmitate sedangkan biodisel jagung terutama tersusun dari Methyl Linoleate dan cis-9 Oleic Methyl Ester.
Struktur asam lemak yang dominan pada biodisel jatropha maupun biodisel jagung ditunjukkan pada Tabel 3. Berdasarkan ada atau tidaknya ikatan rangkap, asam lemak dapat dibedakan menjadi asam lemak jenuh dan asam lemak tak jenuh. Asam lemak tak jenuh adalah asam lemak yang memiliki ikatan rangkap. Methyl linoleate dan cis 9 oleic methyl ester merupakan asam lemak tak jenuh dengan konfigurasi cis. Konfigurasi cis menyebabkan molekul agak melengkung, sedangkan molekul dengan konfigurasi trans relatif lurus. Linolelaidic acid methyl ester adalah asam lemak dengan ikatan rangkap konfigurasi trans. Adapun methyl palmitate adalah asam lemak jenuh.

Karakteristik biodisel jatropha dan biodisel jagung disampaikan pada Tabel 4. Terlihat bahwa setelah diproses menjadi biodisel, viskositas minyak berubah signifikan. Viskositas biodisel jatropha jauh lebih tinggi dari biodisel minyak jagung.

TABEL 2. Kandungan asam lemak pada biodisel jatropha dan biodiesel jagung (\%)

\begin{tabular}{lcrr}
\hline Asam Lemak & Rumus Molekul & Biodisel Jatropha & Biodisel Jagung \\
\hline M Butyrate & $\mathrm{C}_{5} \mathrm{H}_{10} \mathrm{O}_{2}$ & 1,02 & 8,85 \\
M Laurate & $\mathrm{C}_{13} \mathrm{H}_{26} \mathrm{O}_{2}$ & 0,12 & - \\
M Tetradecanoate & $\mathrm{C}_{15} \mathrm{H}_{30} \mathrm{O}_{2}$ & 0,78 & - \\
M Palmitate & $\mathrm{C}_{17} \mathrm{H}_{34} \mathrm{O}_{2}$ & 39,08 & 10,85 \\
M Palmitoleate & $\mathrm{C}_{17} \mathrm{H}_{32} \mathrm{O}_{2}$ & 0,15 & - \\
M Octadecanoate & $\mathrm{C}_{19} \mathrm{H}_{38} \mathrm{O}_{2}$ & - & 1,4 \\
Trans-9-Elaidic acid Methyl ester & $\mathrm{C}_{19} \mathrm{H}_{36} \mathrm{O}_{2}$ & 3,96 & - \\
Cis-9-Oleic Methyl ester & $\mathrm{C}_{19} \mathrm{H}_{36} \mathrm{O}_{2}$ & - & 29,64 \\
Linolelaidic Acid Methyl Ester & $\mathrm{C}_{19} \mathrm{H}_{34} \mathrm{O}_{2}$ & 44,04 & - \\
M Linoleate & $\mathrm{C}_{19} \mathrm{H}_{34} \mathrm{O}_{2}$ & 10,24 & 47,86 \\
M Linolenate & $\mathrm{C}_{19} \mathrm{H}_{32} \mathrm{O}_{2}$ & 0,14 & 0,24 \\
M Arachidate & $\mathrm{C}_{21} \mathrm{H}_{42} \mathrm{O}_{2}$ & - & 0,43 \\
Methyl cis-11-eicosenoate & $\mathrm{C}_{21} \mathrm{H}_{40} \mathrm{O}_{2}$ & 0,47 & 0,72 \\
\hline
\end{tabular}

TABEL 3. Asam lemak dominan pada biodisel jatropha dan biodiesel jagung

\begin{tabular}{lll}
\hline Asam lemak & Rumus Molekul & Singkatan \\
\hline Linolelaidic Acid Methyl Ester & $\mathrm{C}_{19} \mathrm{H}_{34} \mathrm{O}_{2}$ & $\mathrm{C} 18: 2$ \\
Methyl Palmitate & $\mathrm{C}_{17} \mathrm{H}_{34} \mathrm{O}_{2}$ & $\mathrm{C} 16: 0$ \\
Methyl linoleate & $\mathrm{C}_{19} \mathrm{H}_{34} \mathrm{O}_{2}$ & $\mathrm{C} 18: 2$ \\
Cis-9-Oleic Methyl ester & $\mathrm{C}_{19} \mathrm{H}_{36} \mathrm{O}_{2}$ & $\mathrm{C} 18: 1$ \\
\hline
\end{tabular}

TABEL 4. Sifat fisik biodiesel jatropha dan biodiesel jagung

\begin{tabular}{lcc}
\hline Sifat biodisel & Minyak Jatropha & Minyak Jagung \\
\hline Densitas, $40{ }^{\circ} \mathrm{C}\left(\mathrm{kg} / \mathrm{m}^{3}\right)$ & 896.7 & 858.2 \\
Viskositas kinematik, $40{ }^{\circ} \mathrm{C}(\mathrm{cSt})$ & 16.98 & 5.37 \\
Titik Nyala $\left({ }^{\circ} \mathrm{C}\right)$ & 202.3 & 165.6 \\
Nilai Kalor $(\mathrm{MJ} / \mathrm{kg})$ & 36.54 & 39.85 \\
\hline
\end{tabular}




\section{Densitas}

Jumlah energi dari bahan bakar yang masuk ke ruang bakar dipengaruhi oleh densitas bahan bakar. Bahan bakar diinjeksikan ke ruang bakar berbasis volume, sehingga massa bahan bakar yang masuk tergantung dari densitas bahan bakar tersebut (Demirbas, 2008). Gambar 1 menunjukkan perubahan densitas campuran biodisel jatropha dan biodisel jagung. Semakin banyak persentase biodisel jagung, maka densitas campuran biodisel semakin rendah.

Densitas campuran biodisel tersebut memenuhi SNI (Biodiesel SNI 7182_2015. Standar Nasional Indonesia, 2015), kecuali densitas biodisel jatropha murni dan campuran biodisel jatropha 90\%. Namun nilai densitas biodisel jatropha lebih rendah daripada hasil penelitian Pramanik (2003), demikian juga densitas biodisel jagung lebih rendah dari densitas yang disampaikan El Boulifi et al., (2010) maupun Shehata et al, (2015).

\section{Viskositas}

Viskositas merupakan sifat penting dari bahan bakar. Viskositas yang tinggi menyebabkan bahan bakar sulit dikabutkan dan ukuran butirnya relatif besar. Viskositas yang tinggi juga menyebabkan sempitnya sudut injeksi (Agarwal \& Agarwal, 2007).

Viskositas kinematik dipengaruhi secara signifikan oleh struktur pembentuk dari minyaknya seperti panjang rantai, posisi, jumlah, dan ikatan rangkapnya (Martínez et al., 2014). Biodisel jagung didominasi oleh methyl linoleate dan cis-9-oleic methyl ester yang merupakan asam lemak tak jenuh. Hal tersebut menyebabkan viskositas biodisel jagung lebih rendah daripada viskositas biodisel jatropha. Gambar 2 menunjukkan perubahan viskositas biodisel jatropha setelah pencampuran dengan biodisel jagung pada berbagai variasi komposisi.

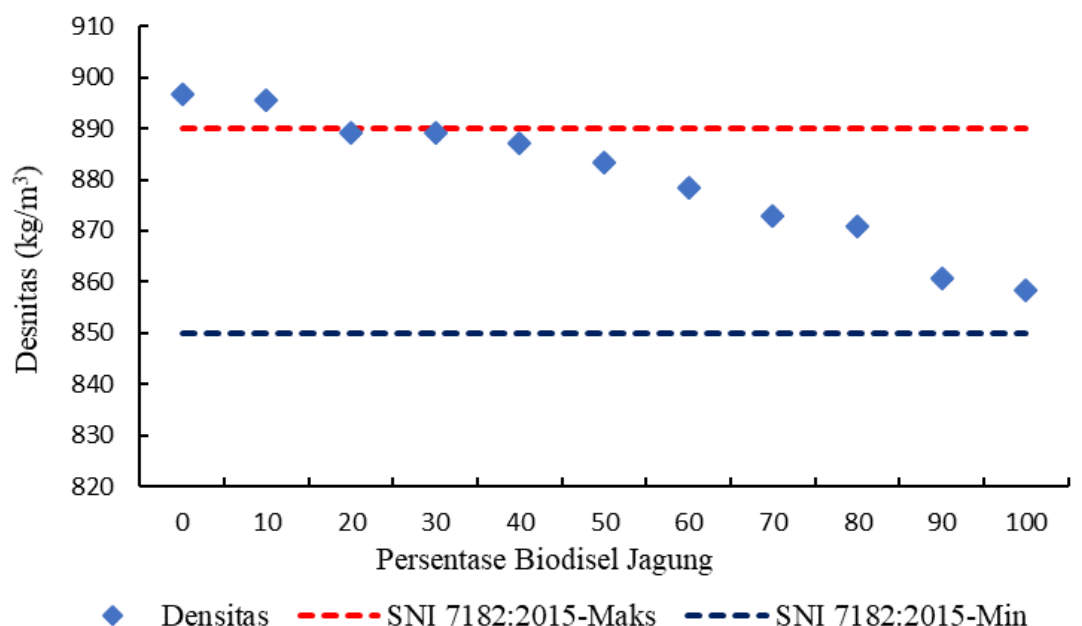

GAMBAR 1. Densitas campuran biodisel jatropha dan biodisel jagung

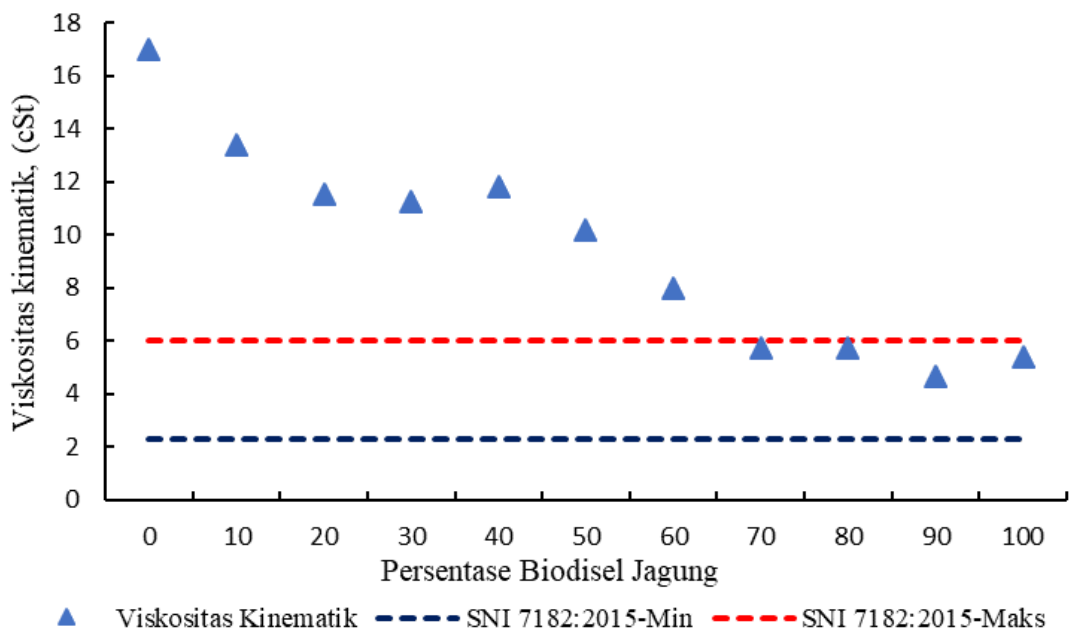

GAMBAR 2. Viskositas kinematik campuran biodisel jatropha dan biodisel jagung 
Viskositas campuran biodisel semakin rendah dengan semakin tingginya persentase biodisel jagung. Pencampuran biodisel jagung membuat penurunan viskositas cukup signifikan, namun yang dapat memenuhi SNI adalah campuran biodisel dengan persentase biodisel jagung di atas 70\%. Viskositas kinematik biodisel jatopha dan jagung lebih tinggi daripada yang disampaikan oleh El Boulifi et al., (2010), Sarin et al.,( 2007) dan Shehata et al., (2015).

Viskositas kinematik berbanding lurus dengan panjang rantai karbon dan berbanding terbalik dengan jumlah ikatan rangkapnya . Semakin panjang rantai karbon asam lemak dan alkohol maka viskositas semakin tinggi, namun sebaliknya viskositas semakin rendah jika ikatan rangkap semakin banyak (Hoekman et al., 2012).

\section{Nilai Kalor}

Nilai kalor menunjukkan kandungan energi suatu bahan bakar. Semakin tinggi nilai kalor suatu bahan bakar berarti semakin banyak energi yang terkandung pada bahan bakar tersebut.

Nilai kalor campuran biodisel meningkat seiring dengan bertambahnya komposisi biodisel jagung, sebagaimana yang terlihat pada Gambar 3. Nilai kalor biodisel jagung lebih tinggi daripada nilai kalor biodisel jatropha. Perbedaan nilai kalor ini disebabkan adanya perbedaan komposisi asam lemak penyusunnya. Biodisel jagung memiliki asam lemak yang secara rata-rata lebih panjang rantai karbonnya.

Nilai kalor biodisel jatropha dari penelitian ini sedikit lebih rendah daripada yang disampaikan oleh Pramanik (2003). Namun nilai kalor biodisel jagung lebih tinggi dari nilai kalor yang diberikan Shehata et al., (2015).

\section{Titik Nyala}

Nilai titik nyala sangat penting dalam penyimpanan bahan bakar (Carareto et al., 2012). Titik nyala adalah temperatur terendah dimana suatu bahan bakar menghasilkan sejumlah uap yang cukup untuk terjadinya penyalaan. Semakin tinggi nilai titik nyala, maka bahan bakar tersebut semakin sulit terbakar.

Gambar 4 menunjukkan nilai titik nyala campuran biodisel jatropa-jagung. Walaupun tidak signifikan, terjadi penurunan titik nyala dengan semakin bertambahnya persentase biodisel jagung. Namun seluruh variasi campuran biodisel tersebut memenuhi SNI.

Terjadinya penurunan titik nyala seiring dengan peningkatan komposisi campuran biodisel jagung tersebut mengindikasikan bahwa perubahan komposisi asam lemak dapat mengubah karakteristik dari biodisel. Nilai titik nyala biodisel jatropha dan biodisel jagung ini sesuai dengan hasil penelitian sebelumnya yang dilakukan Sarin et al., (2007) dan Shehata et al., (2015).

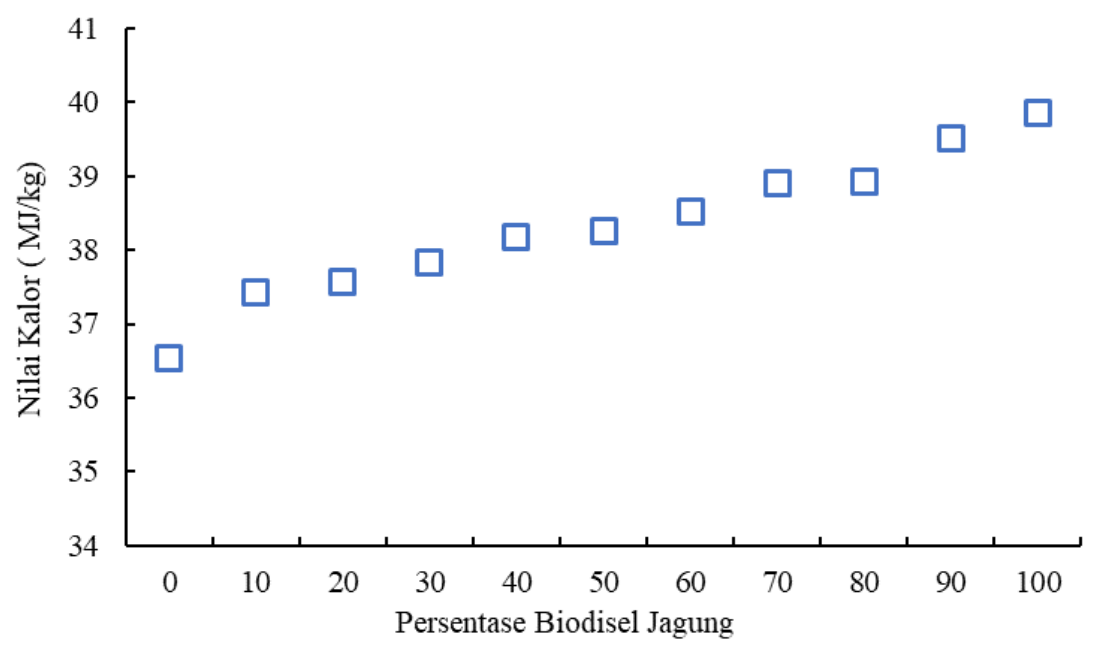

GAMBAR 3. Nilai kalor campuran biodisel jatropha-jagung 


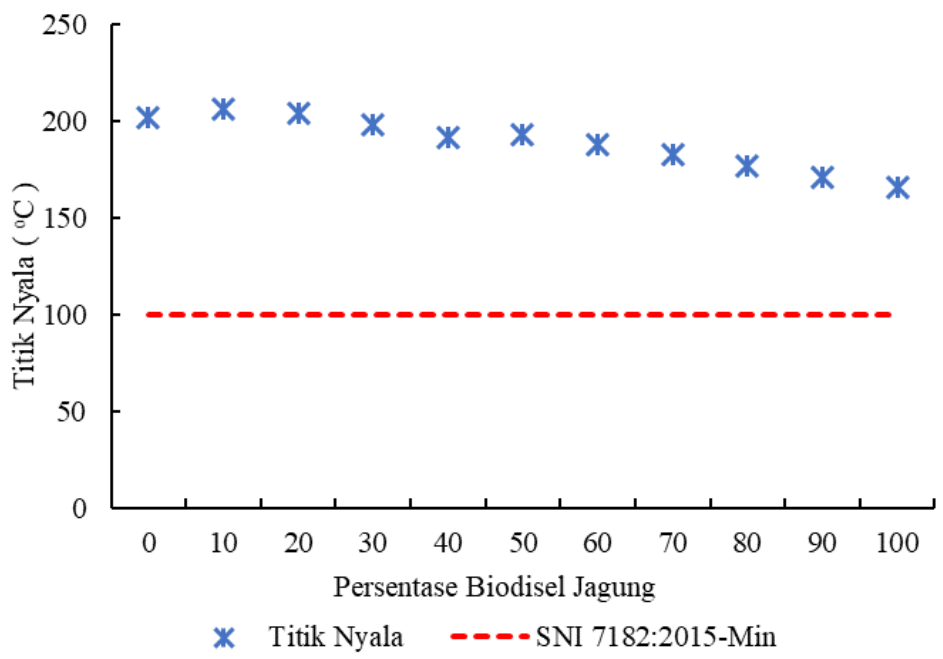

GAMBAR 4. Titik nyala campuran biodisel jatropha-jagung

\section{KESIMPULAN}

Minyak jatropha dan minyak jagung memiliki komposisi asam lemak yang berbeda. Perbedaan komposisi tersebut menyebabkan adanya perbedaan sifat fisiknya. Biodisel jagung lebih banyak mengandung methyl linoleate dan cis-9-oleic methyl ester yang merupakan asam lemak tak jenuh, sehingga densitas, viskositas dan titik nyala biodisel jagung lebih rendah daripada biodisel jatropha, namun nilai kalornya lebih tinggi. Pencampuran biodisel jatropha dengan biodisel jagung menghasilkan perubahan sifat fisik biodisel tersebut.

Viskositas biodisel campuran jatropha-jagung semakin rendah dengan semakin banyaknya persentase biodisel jagung. Selain itu juga menyebabkan densitas dan titik nyala semakin menurun. Namun semakin tinggi persentase biodisel jagung menghasilkan peningkatan nilai kalor pada campuran tersebut. Secara umum, pencampuran biodisel jagung pada biodisel jatropha dapat memperbaiki sifat biodisel jatropha sebagai bahan bakar nonpangan.

\section{DAFTAR PUSTAKA}

Abed, K. A., El Morsi, A. K., Sayed, M. M., El Shaib, A. A., \& Gad, M. S. (2018). Effect of waste cooking-oil biodiesel on performance and exhaust emissions of a diesel engine. Egyptian Journal of Petroleum, 27 (4), 985-989.
Agarwal, D., \& Agarwal, A. K. (2007). Performance and emissions characteristics of Jatropha oil (preheated and blends) in a direct injection compression ignition engine. Applied Thermal Engineering, 27(13), 23142323.

Biodiesel SNI 7182_2015. Standar Nasional Indonesia. (2015).

Carareto, N. D. D., Kimura, C. Y., Oliveira, E. C., Costa, M. C., \& Meirelles, A. J. (2012). Flash points of mixtures containing ethyl esters or ethylic biodiesel and ethanol. Fuel, 96, 319326.

Crabbe, E., Nolasco-Hipolito, C., Kobayashi, G., Sonomoto, K., \& Ishizaki, A. (2001). Biodiesel production from crude palm oil and evaluation of butanol extraction and fuel properties. Process Biochemistry, 37(1), 65-71.

Demirbas, A. (2008). Relationships derived from physical properties of vegetable oil and biodiesel fuels. Fuel, 87(8-9), 1743-1748.

El Boulifi, N., Bouaid, A., Martinez, M., \& Aracil, J. (2010). Process optimization for biodiesel production from corn oil and its oxidative stability. International Journal of Chemical Engineering.

Eloka-Eboka, A. C., Igbum, G. O., \& Inambao, F. L. (2017). Biodiesel methyl ester production and testing from selected African tropical seed oil feedstocks. Energy Procedia, 142, 755-767. 
Gopal, K. N., Pal, A., Sharma, S., Samanchi, C., Sathyanarayanan, K., \& Elango, T. (2014). Investigation of emissions and combustion characteristics of a CI engine fueled with waste cooking oil methyl ester and diesel blends. Alexandria Engineering Journal, 53(2), 281-287.

Hoekman, S. K., Broch, A., Robbins, C., Ceniceros, E., \& Natarajan, M. (2012). Review of biodiesel composition, properties, and specifications. Renewable and Sustainable Energy Reviews, 16(1), 143-169.

Martínez, G., Sánchez, N., Encinar, J. M., \& González, J. F. (2014). Fuel properties of biodiesel from vegetable oils and oil mixtures. Influence of methyl esters distribution. Biomass and Bioenergy, 63, 22-32.

Nisar, J., Razaq, R., Farooq, M., Iqbal, M., Khan, R. A., Sayed, M., Shah, A., and Rahman, I. (2017). Enhanced biodiesel production from Jatropha oil using calcined waste animal bones as catalyst. Renewable Energy, 101, 111-119.

Pramanik, K. (2003). Properties and use of Jatropha curcas oil and diesel fuel blends in compression ignition engine. Renewable Energy, 28(2), 239-248.

Sarin, R., Sharma, M., Sinharay, S., \& Malhotra, R. K. (2007). Jatropha-palm biodiesel blends: An optimum mix for Asia. Fuel, 86(10-11), 1365-1371.

Shehata, M. S., Attia, A. M. A., \& Razek, S. M. A. (2015). Corn and soybean biodiesel blends as alternative fuels for diesel engine at different injection pressures. Fuel, 161, 49-58.

Sidabutar, E. D. C., Faniudin, M. N., \& Said, M. (2013). Pengaruh rasio reaktan dan jumlah katalis terhadap konversi minyak jagung menjadi metil ester. Jurnal Teknik Kimia, 19(1), 40-49.

Silitonga, A. S., Masjuki, H. H., Mahlia, T. M. I., Ong, H. C., Chong, W. T., \& Boosroh, M. H. (2013). Overview properties of biodiesel diesel blends from edible and non-edible feedstock. Renewable and Sustainable Energy Reviews, 22, 346-360.
Wahyudi, W., Nadjib, M., Bari, M. F., \& Permana, F. W. (2019). Increasing of quality biodiesel of Jatropha seed oil with biodiesel mixture of waste cooking oil. Journal of Biotech Research, 10, 183-189.

PenULIS:

Wahyudi

Program Studi Teknik Mesin, Fakultas Teknik, Universitas Muhammadiyah Yogyakarta, Jalan Brawijaya, Tamantirto, Kasihan, Bantul, Yogyakarta.

Email : wahyudi@ft.umy.ac.id

Andre Sasuta

Program Studi Teknik Mesin, Fakultas Teknik, Universitas Muhammadiyah Yogyakarta, Jalan Brawijaya, Tamantirto, Kasihan, Bantul, Yogyakarta.

\section{Muhammad Nadjib}

Program Studi Teknik Mesin, Fakultas Teknik, Universitas Muhammadiyah Yogyakarta, Jalan Brawijaya, Tamantirto, Kasihan, Bantul, Yogyakarta. 